Research Paper

\title{
Dracorhodin Perchlorate Induced Human Breast Can- cer MCF-7 Apoptosis through Mitochondrial Pathways
}

Jing-hua $\mathrm{Yu}^{1^{*}}$, Gui-bin Zheng ${ }^{*}$, Chun-yu Liu ${ }^{*}$, Li-ying Zhang, Hong-mei Gao ${ }^{5}$, Ya-hong Zhang ${ }^{6}$, Chun-yan Dai ${ }^{1}$, Lin Huang 7 , Xian-ying Meng ${ }^{2 \bowtie}$, Wen-yan Zhang ${ }^{1 凶}$, Xiao-fang Yu ${ }^{1 凶}$

1. Institute of virology and AIDS research, The first hospital of Jilin University, Changchun 130021, P. R. China;

2. Department of Thyroid Surgery, The First Hospital of Jilin University, Changchun 130021, P. R. China;

3. Acupunture department, The affiliated hospital to Changchun University of Chinese Medicine, Changchun 130021, P. R. China;

4. Department of Biotechnology, College of Animal Science and Veterinary Medicine, Jilin University, Changchun 130062, P. R. China;

5. Medicinal chemistry, Changchun University of Chinese Medicine, Changchun 130021, P. R. China;

6. Key Laboratory of Natural Medicine and Immuno-Engineering, Henan University, Hennan, Kaifeng 475004, P. R. China;

7. Tumor department of Hematology, the 208th Hospital of PLA, Changchun, 130062, P. R. China.

* Jing-hua Yu, Gui-bin Zheng and Chun-yu Liu are co-first authors.

$\triangle$ Corresponding authors: Department of Thyroid Surgery, The First Hospital of Jilin University, 71 Qianjin Street, Changchun 130021, P. R. China; Tel: (86) 431-88782144, Fax: (86) 431-88782144. Email: 497573398@qq.com. Institute of virology and AIDS research, The first hospital of Jilin University, 519 Dongminzhu Street, Changchun 130021, P. R. China. Tel: (86) 431-88782147, Fax: (86) 431-88782147. Email: wezhang@jhsph.edu; xfyu@jhsph.edu

( ) Ivyspring International Publisher. This is an open-access article distributed under the terms of the Creative Commons License (http://creativecommons.org/ licenses/by-nc-nd/3.0/). Reproduction is permitted for personal, noncommercial use, provided that the article is in whole, unmodified, and properly cited.

Received: 2013.03.19; Accepted: 2013.06.13; Published: 2013.07.07

\begin{abstract}
Objective: Dracorhodin perchlorate (DP) was a synthetic analogue of the antimicrobial anthocyanin red pigment dracorhodin. It was reported that DP could induce apoptosis in human prostate cancer, human gastric tumor cells and human melanoma, but the cytotoxic effect of DP on human breast cancer was not investigated. This study would investigate whether DP was a candidate chemical of anti-human breast cancer.

Methods: The MTT assay reflected the number of viable cells through measuring the activity of cellular enzymes. Phase contrast microscopy visualized cell morphology. Fluorescence microscopy detected nuclear fragmentation after Hoechst 33258 staining. Flowcytometric analysis of Annexin V-PI staining and Rodamine 123 staining was used to detect cell apoptosis and mitochondrial membrane potential (MMP). Real time PCR detected mRNA level. Western blot examined protein expression.

Results: DP dose and time-dependently inhibited the growth of MCF-7 cells. DP inhibited MCF-7 cell growth through apoptosis. DP regulated the expression of $\mathrm{Bcl}-2$ and $\mathrm{Bax}$, which were mitochondrial pathway proteins, to decrease MMP, and DP promoted the transcription of Bax and inhibited Bcl-2. Apoptosis-inducing factor (AIF) and cytochrome $\mathrm{c}$ which localized in mitochondrial in physiological condition were released into cytoplasm when MMP was decreased. DP activated caspase-9, which was the downstream of mitochondrial pathway. Therefore DP decreased MMP to release AIF and cytochrome $\mathrm{c}$ into cytoplasm, further activating caspase 9, lastly led to apoptosis.

Conclusion: Therefore DP was a candidate for anti-breast cancer, DP induced apoptosis of MCF-7 through mitochondrial pathway.
\end{abstract}

Key words: dracorhodin perchlorate; apoptosis; mitochondrial pathway

\section{Introduction}

Dracorhodin perchlorate (DP, Fig. 1A) was a synthetic analogue of the antimicrobial anthocyanin red pigment dracorhodin (Fig. 1B), which was isolated in the exudates of the fruit of Daemonorops draco 
[1-3] in traditional Chinese medicine named as "dragon's blood". It had been previously proved that loureirin B, one of extracted compounds from Daemonorops draco, could modulate sodium currents and exert biological activity [4]. Therefore the evaluation of the biological effects of other active compounds from Daemonorops draco could be helpful for new drug development. In 2012, Rasul A et al. [5] found that DP inhibits PI3K/Akt and NF-kB activation, up-regulates the expression of p53. And He et al. [6] also reported that DP suppressed proliferation and induced apoptosis in human prostate cancer cells. Other studies have shown that DPinhibited cell growth and triggered apoptosis in melanoma and leukemic cancer cells $[7,8]$, but the effect of anti-human breast cancer MCF-7 cells of DP was not investigated. MCF-7 cells was one kind of cell which did not express caspase-3 due to the functional 47-bp deletion inside the exon 3 of the CASP-3 gene, but remained the activity of caspase8, caspase9 and caspase 7 [9-12]. Actually when caspase- 3 had no contribution to cell death, cells could still die apoptotically by non-caspase-3dependent or caspase-independent mechanisms [13-15]. This study aimed to investigate the inhibitory role of DP on MCF-7 cells and the molecular mechanism of DP-induced apoptosis in caspase 3-deficient MCF-7 cells.

Apoptosis, the process of programmed cell death (PCD), had many kinds of apoptotic mechanism. One was Fas death receptor pathway was involved in the activation of caspase- 8 and caspase- 10 [16, 17]. Another important one was mitochondrial pathway [18]. Once cytochrome c was released, it would bind with apoptotic protease activating factor - 1 (Apaf-1) and ATP, which then bind to pro-caspase- 9 to create a protein complex known as an apoptosome. Mitochondrial outer membrane permeabilization pore was regulated by various proteins, such as Bcl-2 and Bax of mammalian Bcl-2 family $[19,20]$. Finally, caspase- 8 and caspase- 9 would activate caspase- 3 to induce apoptosis. Because MCF-7 cells did not express caspase-3 [9], therefore we observed the release of apoptotic factor, apoptosis-inducing factor (AIF) which belonged to caspase-independent pathway, from mitochondria. AIF was a protein that could trigger chromatin condensation and DNA degradation in a cell in order to induce programmed cell death, likely caspase 3 which could condense chromatin and fragmented DNA [21-23].

The goal of this study was to identify a novel anti-human breast cancer agent and the role of mitochondrial pathway in DP-treated MCF-7 cells.

\section{Materials and methods}

\section{Regents}

Dracorhodin perchlorate (DP), which was purchased from the National Institute for the Control of Pharmaceutical and Biological Products (Beijing, China), was dissolved in DMSO to make a stock solution. The DMSO concentration was kept below 0.01\% in all the cell cultures, and did not exert any detectable effect on cell growth or cell death. Propidium iodide (PI), Hoechst 33258, RNase A, proteinase K, 3-(4,5-dimethylthiazol-2-yl)-2,5-diphenyltetrazolium bromide (MTT) were purchased from Sigma (St Louis, MO, USA). Trizol reagent and SuperScript TM III RT-PCR Kit from Invitrogen (Carlsbad, CA, USA). Power SYBR Green PCR Master Mix was from ABI (Vernon, CA, USA). Caspase-9 inhibitor, polyclonal antibodies against bax, bcl-2, cytochrome c, apoptosis-inducing factor (AIF), caspase-9, $\beta$-actin, and horseradish peroxidase-conjugated secondary antibodies (goat-anti rabbit) were obtained from Santa Cruz Biotechnology (Santa Cruz, CA, USA). Annexin V- PI staining kit was obtained from $\mathrm{BD}$ pharmingen( $\mathrm{BD}, \mathrm{SD}, \mathrm{USA})$

\section{Cell culture}

Human breast cancer MCF-7 cells were obtained from American Type Culture Collection (Manassas, VA, USA) and were cultured in RPMI-1640 medium (Hyclone, Logan, UT, USA) supplemented with $10 \%$ heat-inactivated $\left(56{ }^{\circ} \mathrm{C}, 30 \mathrm{~min}\right)$ fetal calf serum (Beijing Yuanheng Shengma Research Institution of Biotechnology, Beijing, China), $2 \mathrm{mmol} / \mathrm{L}$ glutamine (Gibco, Grand Island, NY, USA), penicillin (100 $\mathrm{U} / \mathrm{mL})$, and streptomycin $(100 \mu \mathrm{g} / \mathrm{mL})$, and maintained at $37{ }^{\circ} \mathrm{C}$ with $5 \% \mathrm{CO}_{2}$ in a humidified atmosphere.

\section{Cell growth inhibition test}

The inhibition of cell growth was determined by a MTT test. The MCF-7 cells $\left(1.5 \times 10^{4}\right.$ cells/well $)$ were seeded into 96-well culture plates (Nunc, Roskilde, Denmark). After overnight incubation, various concentrations of DP were added to the plates. MCF-7 cells were treated with $60 \mu \mathrm{mol} / \mathrm{L}$ DP for $24 \mathrm{~h}$, and/or $20 \mu \mathrm{mol} / \mathrm{L}$ caspase 9 inhibitor, and following incubation, cell growth was measured at different time points by the addition of MTT at $37^{\circ} \mathrm{C}$ for $3 \mathrm{~h}$; DMSO $(150 \mu \mathrm{L})$ was added to dissolve the formazan crystals. Absorbance was measured at $492 \mathrm{~nm}$ with an ELISA plate reader (Bio-Rad, Hercules, CA, USA). The percentage of inhibition was calculated as follows:

Inhibitory ratio $(\%)=\left(\mathrm{A}_{492}\right.$ [control] $-\mathrm{A}_{492}[\mathrm{sam}-$ ple] $) / \mathrm{A}_{492}$ [control] $\times 100 \%$. 


\section{Observation of morphological changes by light microscopy}

The MCF-7 cells were treated with $60 \mu \mathrm{mol} / \mathrm{L}$ $\mathrm{DP}$ for $24 \mathrm{~h}$, and/or $20 \mu \mathrm{mol} / \mathrm{L}$ caspase 9 inhibitor, the morphological changes were observed by phase contrast microscopy (Leica, Nusslich, Germany).

\section{Nuclei fragmentation observed by Hoechst 33258 staining}

The MCF-7 cells, which were incubated in RPMI-1640 containing 10\% fetal calf serum, were seeded into 6-well plates (Nunc, Denmark) with coverslips and cultured overnight. The cells were treated with 0 and $60 \mu \mathrm{mol} / \mathrm{L} \mathrm{DP} 24 \mathrm{~h}$. The morphological changes of the nuclei were observed by Hoechst 33258 staining. The cells on the coverslips were rinsed and stained with Hoechst $(10 \mathrm{mg} / \mathrm{L})$ at 37 ${ }^{\circ} \mathrm{C}$ for $30 \mathrm{~min}$. After the coverslips were sealed, the samples were observed by fluorescence microscopy (Leica, Germany).

\section{Flowcytometric apoptosis analysis by Annex- in-PI staining}

Washed cells twice with cold PBS and then resuspended cells in $1 \mathrm{X}$ Binding Buffer at a concentration of $1 \times 10^{6}$ cells $/ \mathrm{ml}$. After that transferred $100 \mu \mathrm{l}$ of the solution $\left(1 \times 10^{5}\right.$ cells $)$ to a $5 \mathrm{ml}$ culture tube. And added $5 \mu \mathrm{l}$ of FITC Annexin V and $5 \mu \mathrm{l}$ PI. Gently vortexed the cells and incubated for $15 \mathrm{~min}$ at RT $\left(25^{\circ} \mathrm{C}\right)$ in the dark. And added $400 \mu \mathrm{l}$ of $1 \mathrm{X}$ Binding Buffer to each tube. Finally analyzed by flow cytometry within $1 \mathrm{~h}$.

\section{Flowcytometric mitochondrial membrane potential (MMP) analysis by the rhodamine I 23 staining}

MCF-7 cells were harvested and rinsed with PBS. Then the cells were stained with $5 \mu \mathrm{g} / \mathrm{ml}$ rhodamine 123 at $37{ }^{\circ} \mathrm{C}$ for $30 \mathrm{~min}$. After incubation, the cells were washed once with PBS. The samples were analyzed by flowcytometry.

\section{Quantitative real-time PCR}

Total RNA of cell samples were isolated using Trizol reagent according to the manufacturer's protocol. Equal amounts of RNA were used to generate the first strand cDNA using SuperScriptTM III RT-PCR Kit (Invitrogen, USA), and the quantitative real-time PCR was performed on the ABI 7300 PCR System (Applied Biosystems, USA) using Power SYBR Green PCR Master Mix (ABI, USA). The relative expression levels of target genes were obtained by the software SDS v1.3.2 attached with the PCR machine; mRNA expression of each target gene was normalized to GAPDH. Sequences of PCR primers are shown.
AAGC

Bax: Forward primer GATGCGTCCACCAAG

Reverse primer AAGTCCAATGTCCAGCCCAT

Bcl-2: Forward primer TGTGTGGAGAGCGTCA AACC

Reverse primer TGGATCCAGGTGTGCAGGT

Caspase-9: Forward primer CTGAGCCAGAT

GCTGTCCCAT

GGAA

Reverse primer CCAAGGTCTCGATGTACCA

GAPDH: Forward primer TGAACGGGAAG CTCACTGG

GTC

Reverse primer GCTTCACCACCTTCTTGAT

\section{Western blot analysis of protein expression}

The MCF-7 cells were treated with $60 \mu \mathrm{mol} / \mathrm{L}$ DP for the indicated times. Both adherent and floating cells were collected and frozen at $-80^{\circ} \mathrm{C}$. A Western blot analysis was performed for the total proteins as follows. Briefly, the cell pellets were resuspended in lysis buffer, including $50 \mathrm{mmol} / \mathrm{L}$ HEPES ( $\mathrm{pH}$ 7.4), $1 \%$ Triton-X 100, $2 \mathrm{mmol} / \mathrm{L}$ sodium orthovanadate, $100 \mathrm{mmol} / \mathrm{L}$ sodium fluoride, $1 \mathrm{mmol} / \mathrm{L}$ EDTA, 1 $\mathrm{mmol} / \mathrm{L}$ egtazic acid (EGTA), $1 \mathrm{mmol} / \mathrm{L}$ phenylmethylsulfonyl fluoride (PMSF), $0.1 \mathrm{~g} / \mathrm{L}$ aprotinin, and $0.01 \mathrm{~g} /$ L leupeptin, then lysed at $4{ }^{\circ} \mathrm{C}$ for $1 \mathrm{~h}$. After 13 $000 \times g$ centrifugation for $10 \mathrm{~min}$, the protein content of the supernatant was determined using Bio-Rad protein assay reagent (Bio-Rad, USA). The protein was loaded in each lane, then separated by $12 \%$ SDS-PAGE, and blotted onto a nitrocellulose membrane. The protein expression was detected using primary polyclonal antibody (1:200-1000) and secondary polyclonal antibody (1:500) conjugated with peroxidase.

\section{Statistical analysis}

All data represent at least 3 independent experiments and are expressed as mean \pm S.D. Statistical comparisons were made using Student's $t$-test. $P$-values of less than 0.05 represented a statistically significant difference.

\section{Results}

\section{Cytotoxic effect of DP on cell growth}

DP was a synthetic analogue of the antimicrobial anthocyanin red pigment dracorhodin (Fig. 1A), which was isolated in the exudates of the fruit of Daemonorops draco. To detect the growth inhibition of DP-exposed MCF-7cells, the cells were treated with various doses of DP, ranging from 40 to $150 \mu \mathrm{mol} / \mathrm{L}$ for12, 24, 36, $48 \mathrm{~h}$. DP showed potent suppressive effect on the MCF-7 cells, and the IC50 values were 57 
$\mu \mathrm{mol} / \mathrm{L}$ at $24 \mathrm{~h}$ (Figure 1B). Therefore in the following experiments, we adopted the condition $60 \mu \mathrm{mol} / \mathrm{L}$ at $24 \mathrm{~h}$.

A<smiles></smiles>

Dracorhodin

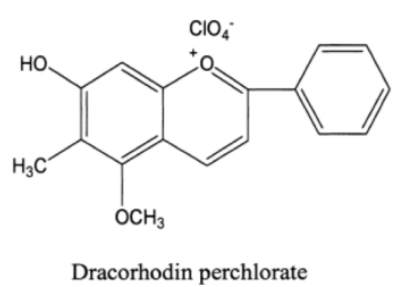

B

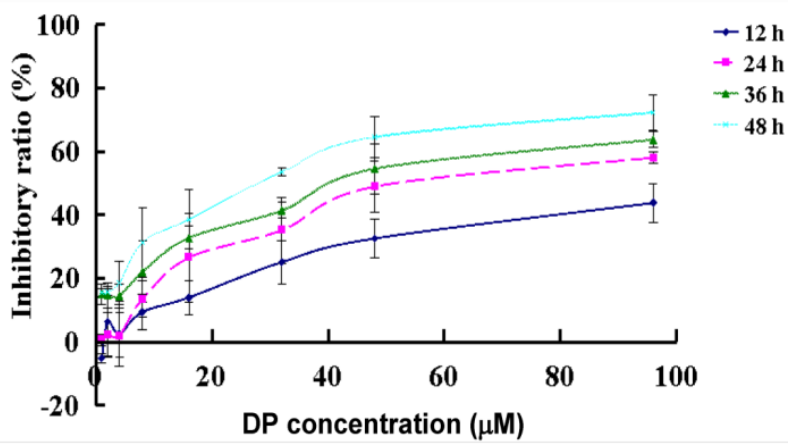

Figure I. Chemical structures of dracorhodin and dracorhodin perchlorate, and the inhibitory effect of dracorhodin perchlorate on MCF-7 cells. A: The structure of dracorhodin and dracorhodin perchlorate; B: Growth inhibition was evaluated by MTT method. Mean $\pm S D, n=3$. DP $=$ dracorhodin perchlorate.

\section{DP induced apoptosis}

Morphological changes were observed by phase contrast microscopy and fluorescence microscopy. At $24 \mathrm{~h}$ after $60 \mu \mathrm{mol} / \mathrm{L} \mathrm{DP}$ treatment, we observed a decreased total cell number, increased floating cells, and the appearance of apoptotic bodies (Figure 2A). Nuclear changes were also detected by hoechst33258. In the control group, the MCF-7 cells were stained blue homogeneously. After $24 \mathrm{~h}$ with $60 \mu \mathrm{mol} / \mathrm{L}$ DP treatment, bright blue nuclei blebbing and nulear fragmentation was observed (Figure 2B). We found that at $18 \mathrm{~h}$ after $60 \mu \mathrm{mol} / \mathrm{L} \mathrm{DP}$ treatment, DP increased Annexin V staining from $0.81 \%$ to $26.52 \%$, further proving that DP induced apoptosis (Figure 2C).

\section{Effect of DP on mitochondrial membrane po- tential (MMP)}

To further investigate the role of MMP in DP-treated MCF-7 cell, a flow cytometric analysis was performed. After $60 \mu \mathrm{mol} / \mathrm{L}$ DP treatment for $24 \mathrm{~h}$,
MMP was decreased from $91.98 \%$ to $24.26 \%$ compared with the control group (Figure 3A), so decreased MMP by DP was one of mechanism of apoptosis.

\section{Bcl-2 family protein in DP-induced MCF-7 cell death}

As shown in Figure 3B, with the time changed, the expression of Bcl-2 protein was decreased, moreover the expression of Bax protein was increased (Figure 3B). And DP increased mRNA level of Bax and decreased mRNA level of Bcl-2 (Figure 3C). Therefore DP changed the transcription of Bax and Bcl-2 to affect their protein expression.

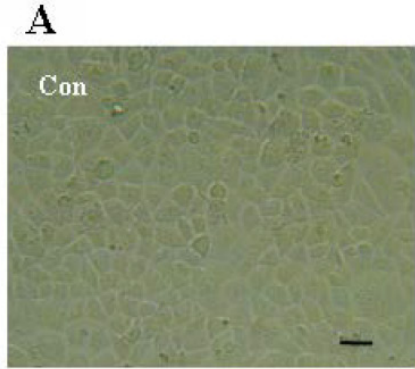

B

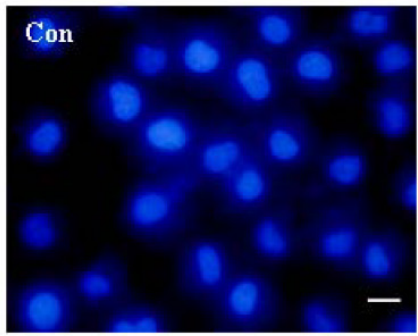

$\mathrm{C}$

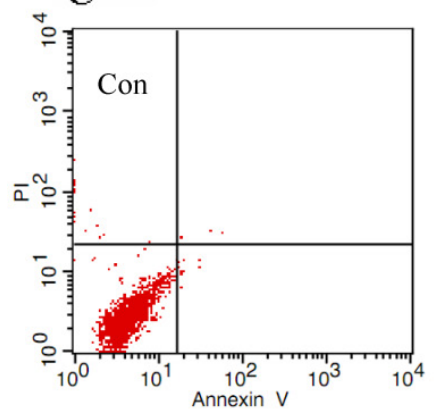

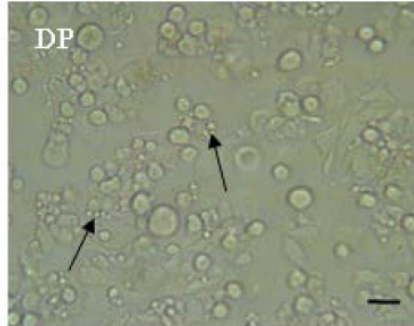
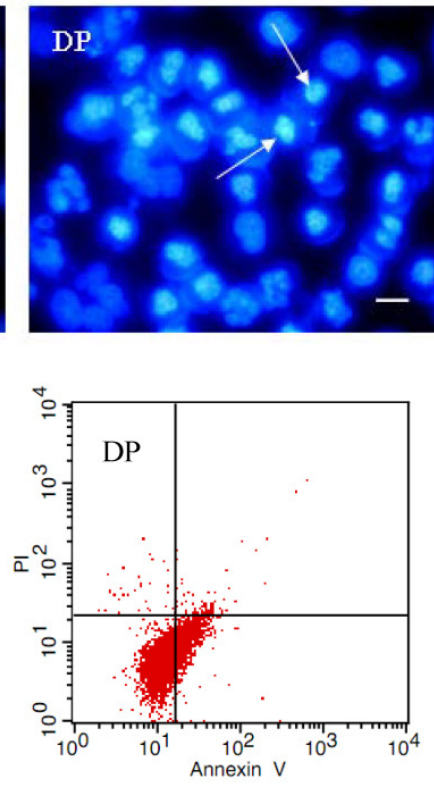

Figure 2. Dracorhodin perchlorate induced MCF-7 cell apoptosis. A: 60 $\mu \mathrm{mol} / \mathrm{L}$ dracorhodin perchlorate for $24 \mathrm{~h}$ promoted the appearance of apoptotic bodies. Arrows in A indicated the apoptotic body. B:60 $\mu \mathrm{mol} / \mathrm{L}$ dracorhodin perchlorate for $24 \mathrm{~h}$ induced nuclei condensed. Arrows in B indicated the condensed nuclei. C: $60 \mu \mathrm{mol} / \mathrm{L}$ dracorhodin perchlorate for $18 \mathrm{~h}$ increased Annexin $\mathrm{V}$ staining from $0.81 \%$ to $26.52 \%$ which marked apoptosis. (A) bar=10 $\mu \mathrm{m}$; (B) bar=5 $\mu \mathrm{m}$. Con: control; DP:dracorhodin perchlorate. 

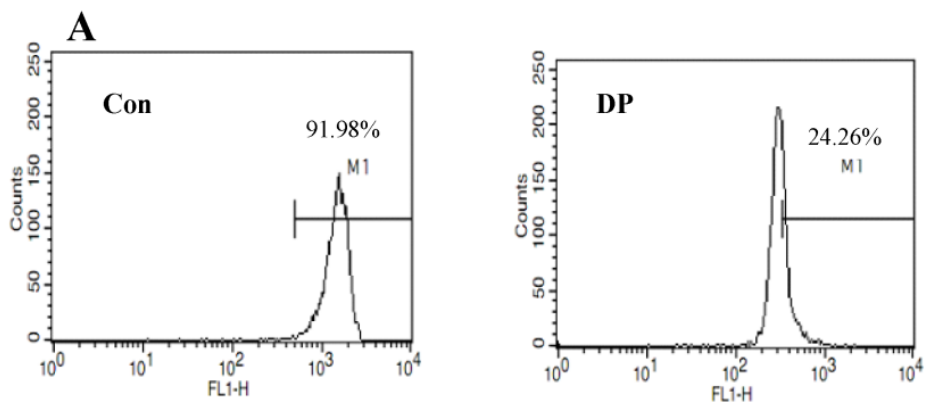

$\begin{array}{lllllll}0 & 6 & 12 & 18 & 24 & 36 & (\text { h })\end{array}$
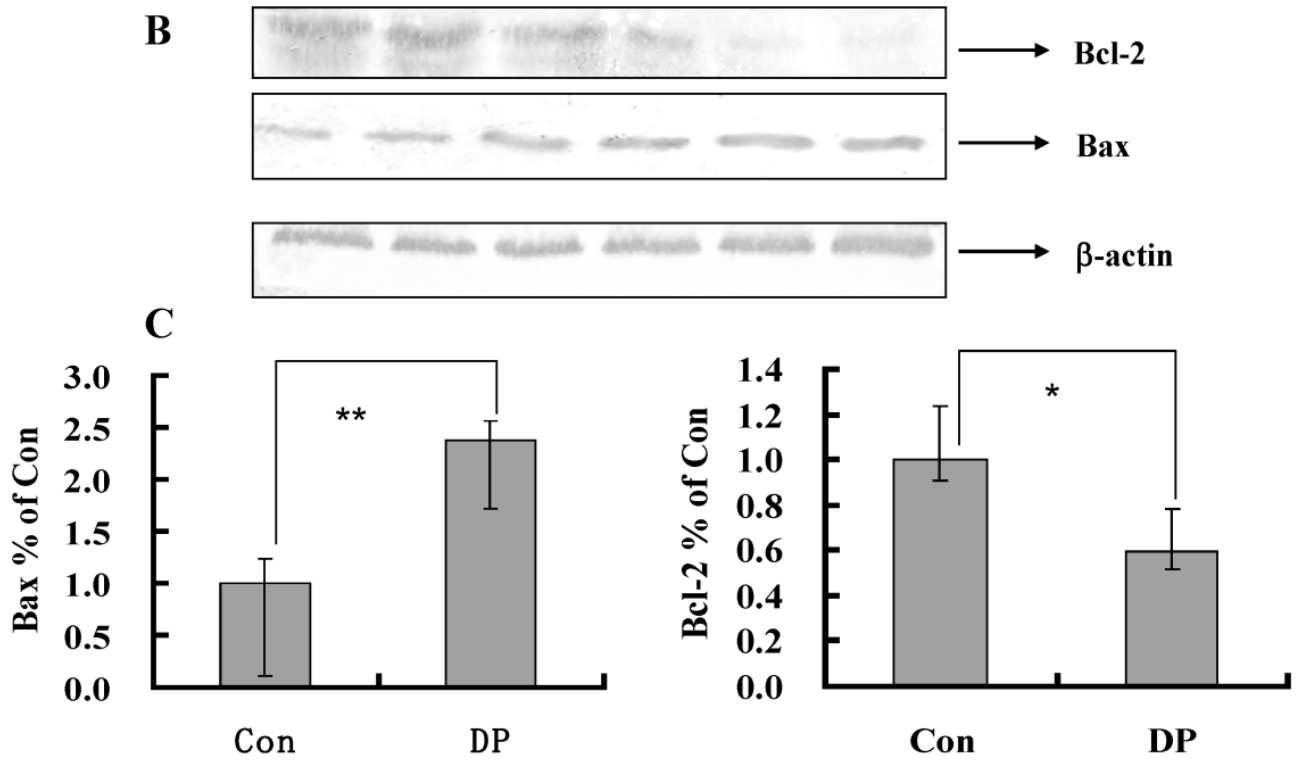

Figure 3 Dracorhodin perchlorate decreased mitochondrial membrane potential, and affected the expression of mitochondrial related protein. A: Cells were treated with $60 \mu \mathrm{mol} / \mathrm{L}$ dracorhodin perchlorate for $24 \mathrm{~h}$, mitochondrial membrane potential were decreased in flowcytometric analysis. B: Treated with $60 \mu \mathrm{mol} / \mathrm{L}$ dracorhodin perchlorate for different time periods, cell lysates were separated by I2\% SDS-PAGE, and the protein expression was detected by Western blot analysis, this is one representative experiment of tri-experiments. C: At $24 \mathrm{~h}$, Dracorhodin perchlorate increased the Bax mRNA level, and decreased the Bcl-2 mRNA level. Mean \pm S.D, $n=3$, * $\mathrm{p}<0.05$ vs. Control. Con: control; DP:dracorhodin perchlorate.

\section{Caspase-9 was activated by DP in MCF-7 cell}

Caspase-9 inhibitor decreased the inhibitory effect of DP in MTT analysis (Figure 4A). From morphologic analysis, it was also proved that caspase-9 inhibitor inhibited the apoptosis induced by DP (Figure 4B). At different time point, the expression of procaspase-9 was decreased, and caspase- 9 was increased (Figure 4C). In our study, caspase -9 was activated by DP time-dependently. But DP did not affect mRNA level of caspase-9(Figure 4D).

\section{Apoptosis-inducing factor (AIF) and cyto- chorome $c$ were released by DP in MCF-7 cell}

Cytochrome $\mathrm{c}$ and AIF were released into cytoplasm after $12 \mathrm{~h}$ of DP treatment (Figure 5).

\section{Discussion}

Breast cancer was a type of cancer originating from breast tissue, most commonly from the inner lining of milk ducts or the lobules that supplied the ducts with milk [24]. Treatments might include surgery, drugs (hormonal therapy and chemotherapy), radiation and/or immunotherapy [25]. But there was no effective drug for therapy and prognosis after surgery. Therefore development of a new and low price drug, especially from traditional Chinese medicine, seems important and urgent, as also previously suggested [26-28]. In this study, we found that dracorhodin perchlorate (DP) dose and time-dependently inhibited MCF-7 cell growth, indicating that DP exerted cytotoxic effect on human breast cancer MCF-7 cell. After DP treatment, apoptotic bodies appeared, nuclei became condensed, and in Annexin V-PI staining single positive of Annexin $\mathrm{V}$ was increased, indicating that DP inhibited MCF-7 cell growth through apoptosis. Since cell growth inhibition may be due not only to apoptosis but also to cell proliferation arrest, future studies will be performed to explore also this issue. 
$\boldsymbol{\infty}$
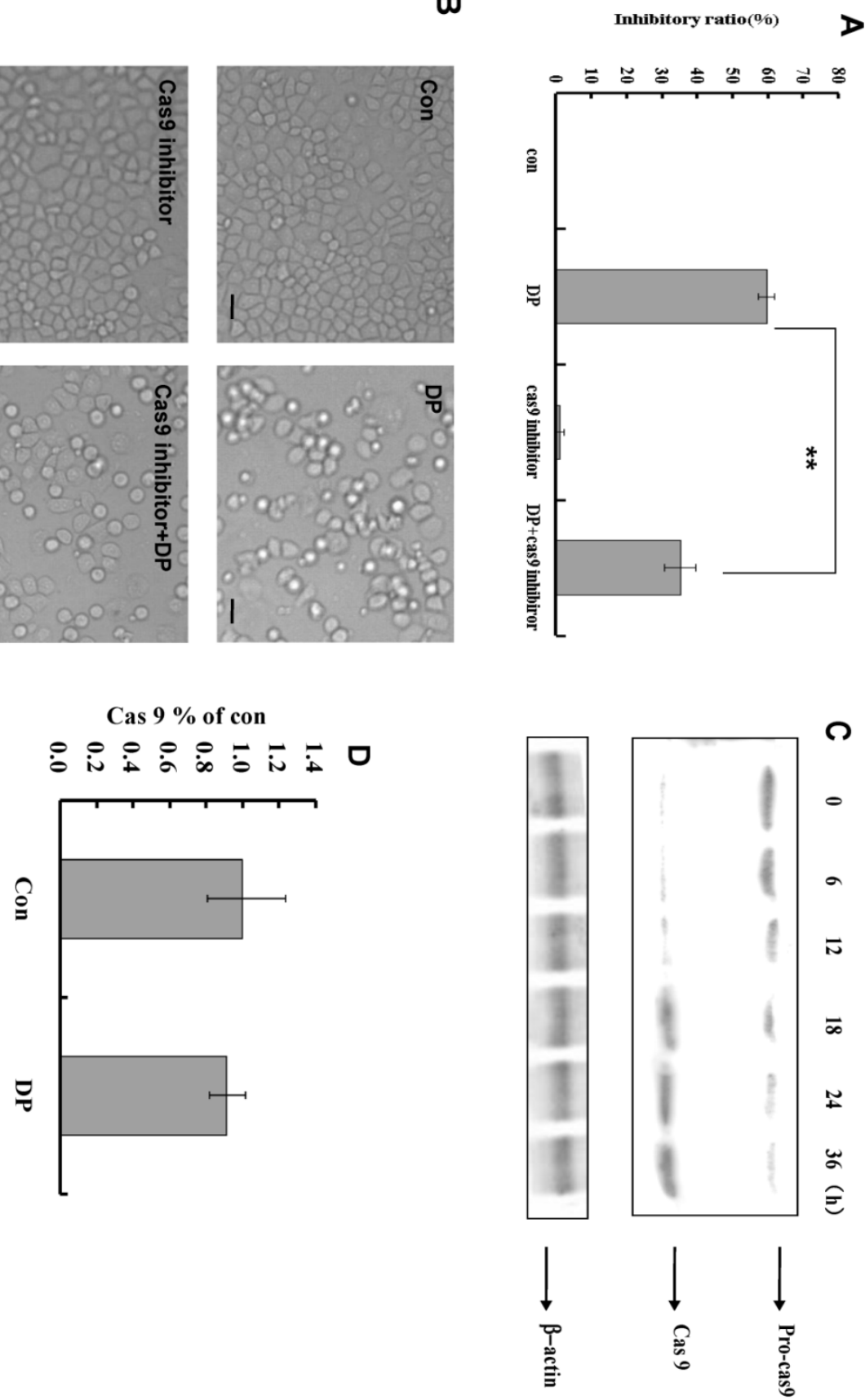

Figure 4. Dracorhodin perchlorate activated caspase- 9 to induce apoptosis. A: caspase- 9 inhibitor decreased the inhibitory ratio of $60 \mu \mathrm{mol} / \mathrm{L}$ dracorhodin perchlorate at $24 \mathrm{~h}$. B: $60 \mu \mathrm{mol} / \mathrm{L}$ dracorhodin perchlorate at $24 \mathrm{~h}$ promoted the appearance of apoptotic bodies, but was inhibited by caspase- 9 inhibitor. C: caspase -9 was activated by dracorhodin perchlorate. D: Dracorhodin perchlorate did not affect the caspase- 9 mRNA. DP:dracorhodin perchlorate.

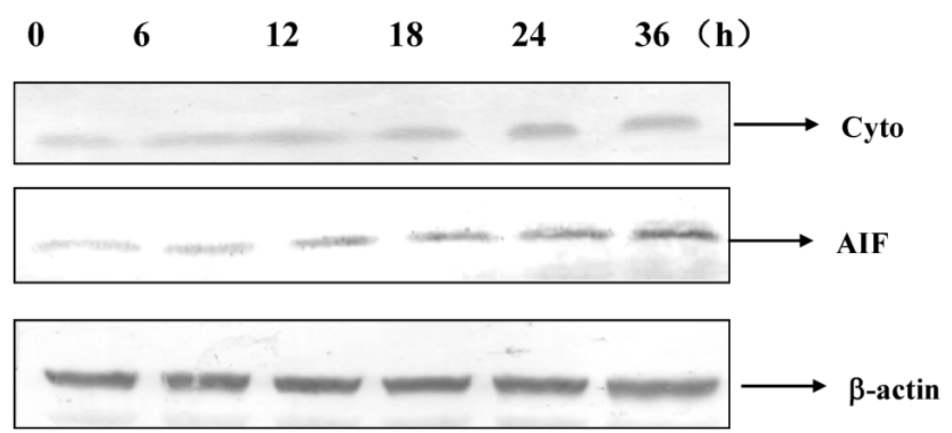

Figure 5. Dracorhodin perchlorate increased the level of cytochrome $c$ and AIF in the cytoplasm. 
It was known that MCF-7 cells did not express caspase-3 due to the functional 47-bp deletion inside the exon 3 of the CASP-3 gene, which was important to apoptosis [9]. Therefore this study would found the apoptotic pathway which was independent on caspase-3. Apoptosis was a complex process, it was found that apoptosis had different pathways, including mitochondrial pathway, Fas death receptor pathway and so on. In this study, DP treatment decreased mitochondrial membrane potential (MMP) and increased the expression of Bax and decreased the expression of Bcl-2, therefore it was supposed that DP treatment decreased the MMP through regulating the expression of Bax and Bcl-2. These results are similar to previous studies in other cancer cell types including A375-S2 human melanoma cells, leukemia and prostate cancer cells [6-8]. We firstly found that DP treatment increased the mRNA level of Bax and decreased the mRNA level of $\mathrm{Bcl}-2$, proving that DP treatment regulated the transcription of Bax and Bcl-2.

AIF (apoptosis inducing factor) was a phylogenetically-conserved mitochondrial intermembrane flavoprotein that had the ability to induce apoptosis in a caspase-independent manner. Previous reports indicated that injection of the anti-AIF antibodies or knockout of the AIF gene might alleviate the progression of apoptosis, suggesting that AIF was required for cell death after certain cell stresses [21-23], therefore we investigated the role of AIF in apoptotic process of DP-treated MCF-7 cells. In this study, AIF was shown to translocate from mitochondria to the cytoplasm after DP treatment, implying apoptosis of MCF-7 cells was independent on caspase 3, but dependent on AIF. Meanwhile cytochrome $c$ was also released into cytoplasm from mitochondria, and activation of caspase 9 was found after DP treatment Therefore DP released cytochrome c to promote the activation of caspase 9. Since cell growth inhibition may be due not only to apoptosis but also to cell proliferation arrest, future studies will be performed to explore also this issue

In conclusion our study strongly suggested a potential role of DP in human breast cancer treatment.

\section{Acknowledgements:}

This work was supported by Administration of Traditional Chinese Medicine of Jilin Province (2012-030).

\section{Competing Interests}

The authors have declared that no competing interest exists.

\section{References}

1. Brockmann H, Junge H. Die Konstitution des Dracorhodins, eines neuen Farbstoffes aus dem "Drachenblut" . Ber Dtsch Chem Ges B. 1943; 76: 751-63.

2. Rao GS, Gerhart MA, Lee RT, et al. Antimicrobial agents from higher plants. Dragon's blood resin. J. Nat. Prod. 1982; 45: 646-8.

3. Gao WF, Zheng H, Wang YS, et al. Synthesis of dracorhodin. Chin J Pharma.1989; 20: 247-50 (in Chinese, abstract in English).

4. Liu X, Yin S, Chen S, et al. Loureirin B: an effective component in dragon's Blood modulating sodium currents in TG neurons. Conf Proc IEEE Eng Med Biol Soc. 2005; 5: 4962-5.

5. Rasul A, Ding C, Li X, et al. Dracorhodin perchlorate inhibits PI3K/Akt and NF-KB activation, up-regulates the expression of p53, and enhances apoptosis. Apoptosis. 2012; 17(10):1104-19.

6. He Y, Ju W, Hao H, et al. Dracorhodin perchlorate suppresses proliferation and induces apoptosis in human prostate cancer cell line PC-3. J Huazhong Univ Sci Technolog Med Sci. 2011; 31(2): 215-9.

7. Xia MY, Wang MW, Cui Z, et al. Dracorhodin perchlorate induces apoptosis in HL-60 cells. J Asian Nat Prod Res.2006; 8(4):335-43.

8. Xia M, Wang M, Tashiro S, et al. Dracorhodin perchlorate induces A375-S2 cell apoptosis via accumulation of p53 and activation of caspases. Biol Pharm Bull. 2005; 28: 226-32

9. Jänicke RU, Sprengart ML, Wati MR, et al. Caspase-3 is required for DNA fragmentation and morphological changes associated with apoptosis. J Biol Chem. 1998; 273(16): 9357-60.

10. Kang KS, Wang P, Yamabe N, et al. Docosahexaenoic acid induces apoptosis in MCF-7 cells in vitro and in vivo via reactive oxygen species formation and caspase 8 activation. PLoS One. 2010; 5(4): e10296.

11. Twiddy D, Cohen GM, Macfarlane M, et al. Caspase-7 is directly activated by the approximately $700-\mathrm{kDa}$ apoptosome complex and is released as a stable XIAP-caspase-7 approximately 200-kDa complex. J Biol Chem. 2006; 281(7): 3876-88.

12. Zoli W, Ulivi P, Tesei A, et al. Addition of 5-fluorouracil to doxorubicin-paclitaxel sequence increases caspase-dependent apoptosis in breast cancer cell lines. Breast Cancer Res. 2005; 7(5): R681-9.

13. Chou CC, Wu YC, Wang YF, et al. Capsaicin-induced apoptosis in human breast cancer MCF-7 cells through caspase-independent pathway. Oncol Rep. 2009; 21(3): 665-71.

14. Choisy-Rossi C, Reisdorf P, Yonish-Rouach E. Mechanisms of p53-induced apoptosis: in search of genes which are regulated during p53-mediated cell death. Toxicol Lett.1998; 102-3:491-6.

15. Lee YJ, Won AJ, Lee J, et al. Molecular mechanism of SAHA on regulation of autophagic cell death in tamoxifen-resistant MCF-7 breast cancer cells. Int J Med Sci. 2012; 9(10): 881-93.

16. Chinnaiyan AM, O'Rourke K, Tewari M, et al. FADD, a novel death domain-containing protein, interacts with the death domain of Fas and initiates apoptosis. Cell.1995; 81(4): 505-12 .

17. Wajant $H$. The Fas signaling pathway: more than a paradigm. Science. $2002 ; 296$ (5573):1635-6 .

18. Nagata S, Golstein P. The Fas death factor. Science.1995; 267:1449-56.

19. Liu X, Kim CN, Yang J, et al. Induction of apoptotic program in cell-free extracts: requirement for dATP and cytochrome c. Cell.1996;86(1):14757.

20. Green DR, Reed JC. Mitochondria and apoptosis. Science. 1998; 281(5381): $1309-12$

21. Norberg E, Orrenius S, Zhivotovsky B. Mitochondrial regulation of cell death: processing of apoptosis-inducing factor (AIF). Biochem Biophys Res Commun. 2010; 396(1): 95-100.

22. Hangen E, Blomgren K, Bénit P, et al. Life with or without AIF. Trends Biochem Sci.2010; 35 (5): 278-87

23. Cande C, Cohen I, Daugas E, et al. Apoptosis-inducing factor (AIF): a novel caspase-independent death effector released from mitochondria. Biochimie. 2002; 84: 215-22

24. Sariego J. Breast cancer in the young patient. Am Sur. 2010; 76 (12):1397-1400.

25. Florescu A, Amir E, Bouganim N, et al. Immune therapy for breast cancer in 2010-hype or hope? . Curr Oncol. 2011; 18 (1): e9-e18.

26. Yu JH, Cui Q, Jiang YY, et al. Pseudolaric acid B induced apoptosis, senescence, and mitotic arrest in human breast cancer MCF-7. Acta Pharmacol Sin. 2007; 28(12):1975-83

27. Yu JH, Li XR, Tashiro SI, et al. Bcl-2 family proteins were involved in Pseudolaric acid B-induced autophagy in murine fibrosarcoma L929 Cells. J Pharmacol Sci. 2008; 107(3): 295-302

28. Yu JH, Liu CY, Zheng GB, et al. Pseudolaric Acid B induced cell cycle arrest, autophagy and senescence in murine fibrosarcoma L929 cell. Int J Med Sci. 2013; 10(6): 707-18. 


\section{Author biography}

Dr Xiao-fang Yu was called back as experts of "Thousand Talents Program" by Organization Department of the CPC Central Committee in 2010, now is working as the director of the Institute of Virology and AIDS Research of Jilin University, who majors in the relationship between virus and host cell, and cancer research, he had published high level of paper in Nature, Science, and so on.

Dr Xian-ying Meng majors in cancer research and clinical therapy of cancer, especially the clinical operation of Thyroid cancer.

Dr Wen-yan Zhang majors in who majors in the relationship between virus and host cell, and cancer research, he had published high level of paper in Nature.

Dr Jing-hua $\mathbf{Y u}$ majors in the relationship of autophagy, apoptosis and cell cycle arrest of cancer cells after drug treatment, and do relative research for 10 years. Currently she focuses on the effect of virus on autophagy, apoptosis and cell cycle arrest of host cells.

Mr Gui-bin Zheng majors in cancer research and clinical therapy of cancer, especially the clinical operation of Thyroid cancer.

Mr Chun-yu liu majors in Chinese medical research and clinical treatment with Chinese medicine. 